\title{
Pengaruh Pembelajaran dengan Model Problem Solving Fisika terhadap Hasil Belajar dan Kemampuan Pemecahan Masalah Fisika Siswa Kelas XI IPA SMAN 1 Lebong
}

\author{
Tiara Veronica, Eko Swistoro, Dedy Hamdani \\ Program Studi Pendidikan Fisika JPMIPA FKIP Universitas Bengkulu \\ Jl Raya Kandang Limun No 1 Bengkulu 38123 \\ Email: tiaraveronica31@gmail.com
}

\begin{abstract}
ABSTRAK
Penelitian ini bertujuan untuk menguji pengaruh pembelajaran yang menggunakan model Problem Solving Fisika (PSF) terhadap hasil belajar pada ranah kognitif dan kemampuan pemecahan masalah fisika. Penelitian dilakukan dengan menggunakan dua jenis disain penelitian yang berbeda, yaitu Quasi Experimental Design dengan bentuk Nonequivalent Control Group Design untuk melihat pengaruh model PSF terhadap hasil belajar kognitif dan Pre-Experimental Design dengan bentuk One Group Pretest-Posttest Group Design untuk melihat pengaruh model PSF terhadap kemampuan pemecahan masalah fisika. Sampel diambil menggunakan teknik purposive sampling dengan kelas XI IPA 2 sebagai kelas eksperimen dan kelas XI IPA 3 sebagai kelas kontrol. Analisis pengaruh model PSF terhadap hasil belajar kognitif dilakukan dengan uji-t dan uji lanjut dengan Cohen's $d$ menggunakan Microsoft Excel 2010. Hasil analisis diperoleh bahwa terdapat pengaruh pembelajaran menggunakan model PSF terhadap hasil belajar kognitif siswa yaitu sebesar 0,72 yang berada dalam kategori sedang. Analisis pengaruh model PSF terhadap kemampuan pemecahan masalah fisika dilakukan dengan perhitungan gain yaitu pengurangan rata-rata posttest dengan pretest dan uji lanjut. Berdasarkan hasil perhitungan diperoleh bahwa model PSF memberikan pengaruh terhadap kemampuan pemecahan masalah fisika siswa sebesar 1,80 yang berada dalam kategori kuat.
\end{abstract}

Kata kunci: Model Problem Solving Fisika, Hasil Belajar Kognitif, Kemampuan Pemecahan Masalah Fisika

\begin{abstract}
This aims of this study was to examine the effect of learning using the Problem Solving Fisika model (PSF) to the learning outcomes in the cognitive domain and physics problem solving skill. The research was conducted using two different types of research designs, namely Quasi Experimental Design with the Nonequivalent Control Group Design form to see the effect of PSF model on cognitive learning outcomes and Pre-Experimental Design with the form of One Group PretestPosttest Group Design to see the effect of PSF model on physics problem solving skill. Samples were taken using purposive sampling technique with class XI IPA 2 as experiment class and class XI IPA 3 as control class. Analysis of the effect of PSF model on cognitive learning outcomes was done with ttest and further test with Cohen's $d$ using Microsoft Excel 2010. The result of analysis obtained that there is effect of learning using PSF model to cognitive learning result of student that is 0,72 which is in medium category. Analysis of the effect of PSF model on the skill of physics problem solving done with the gain calculation is the average posttest reduction with pretest and further test. Based on the calculation results obtained that the PSF model gives effect to the student's skill of physics problem solving that is 1,80 which is in the high category.
\end{abstract}

Keywords: Problem Solving Fisika Model, Cognitive Learning Outcomes, Physics Problem Solving Skill

\section{PENDAHULUAN}

Pembelajaran fisika masih dianggap sulit oleh sebagian besar siswa dan hanya sebagian siswa yang mengganggap fisika itu mudah dan menyenangkan, hal ini dikarenakan siswa masih memiliki kemampuan awal fisika yang kurang [1]. Menurut Hegde (2012) [2], salah satu tujuan penting dalam pembelajaran fisika adalah untuk memastikan siswa mampu mempelajari konsep dan menerapkannya ke dalam situasi baru secara efektif. Selanjutnya menurut Taale (2011) [3] kendala utama dalam pembelajaran fisika adalah siswa yang selalu 
merasa kesulitan dalam memecahkan masalah fisika, sehingga siswa diajarkan untuk mampu memecahkan masalah fisika menggunakan sumber yang ada melalui proses latihan dalam pengkajian fisika. Hal ini berarti bahwa siswa tidak secara langsung memperoleh kemampuan pemecahan masalah fisika dari guru, melainkan melalui proses latihan terus-menerus. Selain itu, siswa harus memiliki pemahaman terhadap konsep fisika untuk bisa memecahkan masalah.

Pembelajaran fisika yang menerapkan kurikulum 2013 telah dilakukan di SMA Negeri 1 Lebong. Model pembelajaran yang kerap diterapkan oleh guru adalah model pengajaran langsung (Direct Instruction). Akan tetapi, hasil belajar fisika masih rendah dan siswa masih belum memahami langkah-langkah pemecahan masalah secara sistematis. Kemampuan pemecahan masalah yang diajarkan masih kemampuan pemecahan masalah sederhana, dimana siswa menuliskan apa yang ditanya, diketahui, dan langsung menjawab dengan menyelesaikan persamaan secara matematis. Sebagian besar siswa masih belum mengetahui langkah apa saja yang harus mereka lakukan untuk memecahkan permasalahan fisika yang diberikan oleh guru. Oleh karena itu, dibutuhkan suatu model pembelajaran yang mampu menunjang pemahaman konsep dan kemampuan pemecahan masalah siswa secara baik, benar, efektif dan menyenangkan [4]. Model pembelajaran yang efektif menurut Aqib dan Mutadlo (2016) [5] adalah model pembelajaran yang memiliki langkah pembelajaran yang sederhana, mudah diterapkan, dapat mencapai hasil belajar optimal, dan salah satu model yang memenuhi kriteria tersebut adalah model problem solving.

Model pembelajaran PSF memiliki lima langkah pembelajaran, yaitu: 1) memahami masalah; 2) menjabarkan masalah ke dalam aspek fisika; 3) merencanakan pemecahan masalah; 4) menjalankan rencana; 5) evaluasi dan perluasan. Pembelajaran menggunakan model PSF ini mengajarkan bagaimana siswa memecahkan masalah fisika yang diberikan oleh guru di kelas, dari langkah pertama hingga langkah ke-empat. Sehingga, kemampuan pemecahan masalah fisika siswa benar-benar diajarkan selama proses pembelajaran berlangsung. Selain itu, model pembelajaran PSF adalah model pembelajaran problem solving yang khusus untuk digunakan dalam pembelajaran fisika. Sehingga, kemampuan pemecahan masalah yang diajarkan bukanlah kemampuan pemecahan masalah secara umum, melainkan kemampuan pemecahan masalah fisika.

Penelitian yang menggunakan model PSF masih sangat jarang dilakukan, terutama di sekolah menengah atas. Oleh sebab itu berdasarkan model pembelajaran PSF yang disarankan oleh Warimun (2010) [6] dilakukan penelitian eksperimen menggunakan model PSF pada topik gelombang bunyi di SMAN 1 Lebong. Berdasarkan uraian di atas, dirumuskan masalah sebagai berikut: 1) Apakah pembelajaran dengan model PSF berpengaruh terhadap hasil belajar kognitif? 2) Apakah pembelajaran dengan model PSF berpengaruh terhadap kemampuan pemecahan masalah fisika? Tujuan penelitian ini adalah untuk menentukan pengaruh model PSF terhadap hasil belajar kognitif dan kemampuan pemecahan masalah fisika siswa pada materi gelombang bunyi.

\section{METODE PENELITIAN}

Jenis penelitian yang digunakan dalam penelitian ini adalah penelitian eksperimen. Sedangkan disain penelitian yang digunakan ada dua yaitu Quasi Experimental Design untuk membandingkan hasil belajar kognitif antara dua kelas, dan Pre-Experimental Design yang digunakan untuk membandingkan kemampuan pemecahan masalah fisika siswa sebelum dan setelah diajarkan dengan model PSF. Penelitian ini dilakukan dengan menggunakan dua disain karena kemampuan pemecahan masalah fisika tidak diajarkan di kelas kontrol.

Penelitian ini dilakukan pada bulan Maret-April 2018 di SMA Negeri 1 Lebong. Sampel diambil dengan teknik purposive sampling melalui pertimbangan guru fisika yang mengajar di kelas XI IPA. Kelas XI IPA 2 digunakan sebagai kelas eksperimen diajarkan menggunakan model PSF dan kelas XI IPA 3 digunakan sebagai kelas kontrol diajarkan menggunkan model pembelajaran yang biasa digunakan oleh guru yaitu Direct Instruction. 
Data dikumpulkan melalui pretest dan posttest hasil belajar kognitif dan kemampuan pemecahan masalah fisika. Tes hasil belajar kognitif (THBK) diberikan di kelas eksperimen dan kelas kontrol, sedangkan tes kemampuan pemecahan masalah fisika (TKPMF) hanya diberikan di kelas eksperimen. Analisis hasil belajar kognitif dan kemampuan pemecahan masalah fisika dilakukan secara terpisah. Pengaruh model PSF terhadap hasil belajar kognitif dianalisis menggunakan uji $\mathrm{t}$ terhadap rata-rata hasil posttest kedua kelas karena data posttest berdistribusi normal dan homogen, serta data pretest yang menunjukkan tidak ada perbedaan. Sedangkan pengaruh model PSF terhadap kemampuan pemecahan masalah fisika diukur dengan menghitung selisih posttest $\left(\mathrm{O}_{2}\right)$ dan pretest $\left(\mathrm{O}_{1}\right)$ TKPMF $\left(O_{2}-O_{1}\right)$. Setelah dilakukan analisis didapatkan bahwa model PSF mempengaruhi hasil belajar kognitif dan kemampuan pemecahan masalah fisika, maka dilakukan uji lanjut untuk mengukur seberapa besar pengaruh model PSF terhadap hasil belajar kognitif dan kemampuan pemecahan masalah fisika siswa.

\subsection{Perhitungan Mean}

Untuk menghitung skor rata-rata hasil belajar digunakan rumus,

$$
\bar{x}=\frac{\sum x_{i}}{n}
$$

$\bar{x}$ adalah rata-rata skor pretest atau skor posttest THBK atau TKPMF yang diperoleh siswa pada tiap pertemuan, $\sum x_{i}$ adalah jumlah tiap data dan $\mathrm{n}$ adalah jumlah sampel.

Menurut Warimun [7], kriteria kemampuan pemecahan masalah adalah: 1) sangat baik jika $80,0<$ mean $\leq 100 ; 2$ ) baik jika $60,0<$ mean $\leq 80,0 ; 3$ ) cukup jika 40,0< mean $\leq 60,0 ; 4$ ) kurang jika 20,0< mean $\leq 40,0$, dan 5) sangat kurang jika $<20,0$.

\subsection{Perhitungan Standar Deviasi}

Untuk menghitung skor standar deviasi atau simpangan baku, digunakan persamaan

$$
s=\sqrt{\frac{n \sum x_{i}^{2}-\left(\sum x_{i}\right)^{2}}{n(n-1)}}
$$

$\mathrm{s}$ adalah standar deviasi (simpangan baku), $\mathrm{n}$ adalah banyaknya sampel, $\sum x_{i}$ adalah jumlah semua skor $\mathrm{x}$ yang ada dalam kumparan itu, dan $\mathrm{x}_{\mathrm{i}}$ adalah skor.

\subsection{Pengujian Hipotesis}

Dalam penelitian ini analisis parametrik yang digunakan untuk menentukan pengaruh model PSF terhadap hasil belajar kognitif adalah uji t karena data rata-rata posttest hasil belajar kognitif yang diperoleh merupakan data yang berdistribusi normal dan homogen. Karena jumlah sampel kelas kontrol dan kelas eksperimen berbeda akan tetapi homogen, maka digunakan rumus poolled varians [8], dengan persamaan sebagai berikut:

$$
t=\frac{\overline{x_{1}}-\overline{x_{2}}}{\sqrt{\frac{\left(n_{1}-1\right) s_{1}^{2}+\left(n_{1}-1\right) s_{2}^{2}}{n_{1}+n_{2}-2}\left(\frac{1}{n_{1}}+\frac{1}{n_{2}}\right)}}
$$

$\mathrm{t}$ adalah skor $\mathrm{t}$ hitung, $\bar{x}_{1}$ adalah skor rata-rata pretest atau posttest hasil belajar kognitif kelas eksperimen, $\bar{x}_{2}$ adalah skor rata-rata pretest atau posttest hasil belajar kognitif kelas kontrol, $n_{1}$ adalah jumlah sampel kelas eksperimen, $n_{2}$ adalah jumlah sampel kelas kontrol, $s_{1}^{2}$ adalah varian kelas eksperimen, dan $s_{2}^{2}$ adalah varian kelas kontrol. Jika harga $t_{\text {hitung }} \leq \mathrm{t}_{\text {tabel }}$ pada taraf signifikansi 0,05 dan derajat kebebasan $(d k)=n_{1}+n_{2}-2$, maka $\mathrm{H}_{0}$ diterima sedangkan $\mathrm{H}_{\mathrm{a}}$ ditolak.

\subsection{Uji Lanjut}

Setelah diperoleh bahwa model pembelajaran Problem Solving Fisika memberikan pengaruh terhadap hasil belajar kognitif, maka dilakukan uji lanjut untuk mencari ukuran pengaruhnya (effect size). Effect size adalah ukuran mengenai besarnya efek atau pengaruh 
suatu variabel terhadap variabel lainnya. Effect size memberikan informasi tentang ukuran (size) dari akibat suatu perlakuan eksperimen (effect) yang sangat penting karena memberikan ukuran seberapa besar pengaruh perlakuan terhadap suatu variabel dalam eksperimen [9]. Perhitungan effect size untuk mengukur besar pengaruh model PSF terhadap hasil belajar kognitif dilakukan dengan menggunakan rumus Cohen's $d$,

$$
d=\frac{\bar{x}_{E}-\bar{x}_{C}}{S_{\text {pooled }}}
$$

dimana,

$$
S_{\text {pooled }}=\sqrt{\frac{\left(n_{E}-1\right) S_{E}^{2}+\left(n_{C}-1\right) S_{C}^{2}}{n_{E}+n_{C}-2}}
$$

$d$ adalah effect size, $\bar{x}_{E}$ adalah rata-rata posttest kelas eksperimen; $\bar{x}_{C}$ adalah rata-rata posttest kelas kontrol; $S_{E}^{2}$ adalah varians kelas eksperimen; $S_{C}^{2}$ adalah varians kelas kontrol. Selanjutnya perhitungan effect size untuk mengukur besar pengaruh model PSF terhadap kemampuan pemecahan masalah fisika dilakukan dengan menggunakan rumus yang berbeda. Alasannya adalah karena disain penelitian yang digunakan adalah One Group Pretest-Posttest Group Design.

$$
d=\frac{\bar{x}_{\text {postest }}-\bar{x}_{\text {pretest }}}{s d}
$$

Standar deviasi yang digunakan merupakan standar deviasi dari perubahan skor pretest dan posttest [10]. Hasil perhitungan effect size diintrepretasikan dengan menggunakan klasifikasi sebagai berikut,

Tabel 1. Klasifikasi Effect Size

\begin{tabular}{ccc}
\hline Cohen's Standard & Effect Size & Persentase (\%) \\
\hline & 2,0 & 97,7 \\
1,9 & 97,1 \\
1,8 & 96,4 \\
& 1,7 & 95,5 \\
1,6 & 94,5 \\
& 1,5 & 93,3 \\
& 1,4 & 91,9 \\
& 1,3 & 90,0 \\
& 1,2 & 88 \\
& 1,1 & 86 \\
& 1,0 & 84 \\
& 0,9 & 82 \\
& 0,8 & 79 \\
\hline \multirow{3}{*}{ Besar } & 0,7 & 76 \\
& 0,6 & 73 \\
& 0,5 & 69 \\
\hline & 0,4 & 66 \\
& 0,3 & 62 \\
& 0,2 & 58 \\
\hline & 0,1 & 54 \\
& 0,0 & 50 \\
\hline
\end{tabular}

\section{HASIL DAN PEMBAHASAN}

\subsection{Pengaruh Model PSF terhadap Hasil Belajar Kognitif}

Kelas eksperimen memperoleh nilai pretest dan posttest yang lebih tinggi daripada kelas kontrol. Rata-rata pretest kelas eksperimen adalah 26,44 dan kelas kontrol 23,84. Rata-rata 
posttest kelas eksperimen adalah 53,63 sedangkan kelas kontrol adalah 45,03. Hasil rata-rata pretest dan posttest THBK kelas kontrol dan kelas eksperimen ditunjukkan oleh Gambar 1.

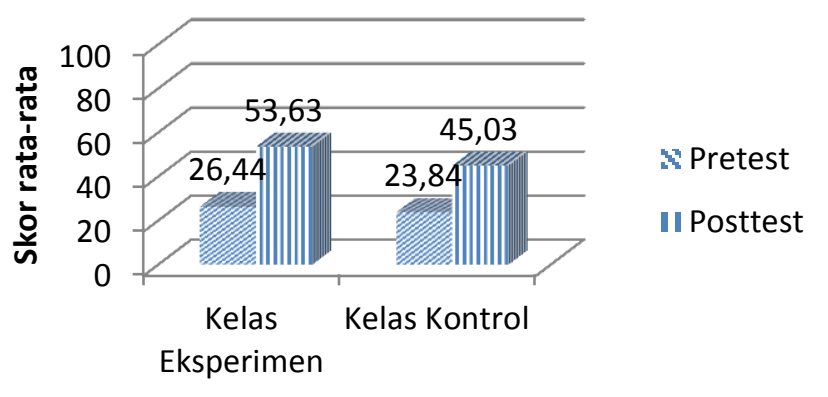

Gambar 1. Rata-rata Pretest dan Posttest THBK Kelas Kontrol dan Kelas Eksperimen

Data hasil uji normalitas rata-rata nilai posttest dengan pretest hasil belajar kognitif masing-masing kelas ditunjukkan oleh Tabel 2.

Tabel 2. Data Hasil Uji Normalitas Rata-rara Pretest dan Posttest Kelas Eksperimen dan Kelas Kontrol

\begin{tabular}{lccccc}
\hline \multirow{2}{*}{ Kelas } & \multirow{2}{*}{ Data } & \multirow{2}{*}{$\chi^{2}$ hitung } & \multicolumn{2}{c}{$\chi^{2}$ tabel } \\
(pada dk=5) & \multirow{2}{*}{ Keterangan } \\
\cline { 3 - 5 } & & & $\boldsymbol{\alpha}=\mathbf{5 \%}$ & $\boldsymbol{\alpha}=\mathbf{1 0 \%}$ & \\
\hline Eksperimen & Rata-Rata Pretest & 8,00 & 11,07 & 9,24 & Berdistribusi normal \\
& Rata-rata Posttest & 4,66 & 11,07 & 9,24 & Berdistribusi normal \\
\hline \multirow{2}{*}{ Kontrol } & Rata-Rata Pretest & 1,29 & 11,07 & 9,24 & Berdistribusi normal \\
& Rata-rata Posttest & 6,11 & 11,07 & 9,24 & Berdistribusi normal \\
\hline
\end{tabular}

Data yang digunakan untuk uji homogenitas adalah sama dengan data yang digunakan pada uji normalitas, yaitu data rata-rata pretest dan rata-rata posttest hasil belajar kognitif kedua kelas. Hasil uji homogenitas kedua kelas bisa dilihat dalam Tabel 3

Tabel 3. Hasil Uji Homogenitas Rata-rata Pretest dan Posttest Kelas Eksperimen dan Kelas Kontrol

\begin{tabular}{ccccc}
\hline \multicolumn{1}{c}{ Kelas } & Jumlah sampel $(\mathbf{n})$ & df & Varians Pretest & Varians Posttest \\
\hline Eksperimen & 30 & 29 & 78,67 & 177,94 \\
Kontrol & 31 & 30 & 53,13 & 111,76 \\
\hline F hitung & & 1,48 & 1,59 \\
\hline F tabel pada $\boldsymbol{\alpha}=\mathbf{5 \%}$ & & 1,84 & 1,84 \\
\hline F tabel pada $\boldsymbol{\alpha}=\mathbf{1 0 \%}$ & \multicolumn{3}{c}{1,61} \\
\hline Syarat & \multicolumn{2}{c}{ F hitung < F tabel } \\
\hline Status varians & HOMOGEN & HOMOGEN
\end{tabular}

Setelah didapatkan bahwa data hasil belajar berdistribusi normal dan homogen, maka dilakukan uji beda. Berikut adalah hasil uji perbedaan nilai posttest dan pretest THBK masing-masing kelas.

Tabel 4. Hasil Uji Perbedaan

\begin{tabular}{clccccccc}
\hline Hasil & \multicolumn{1}{c}{ Kelas } & $\mathbf{n}$ & $\begin{array}{c}\text { Rata- } \\
\text { rata }\end{array}$ & Varians & $\mathbf{t}$ & \multicolumn{2}{c}{$\begin{array}{c}\text { (tabel } \\
\mathbf{( d f = 5 9 )}\end{array}$} & Kesimpul-an \\
& & & & & $\mathbf{5 \%}$ & $\mathbf{1 0 \%}$ & \\
\hline $\begin{array}{c}\text { Rata-rata } \\
\text { Pretest }\end{array}$ & $\begin{array}{l}\text { Eksperime } \\
\mathrm{n}\end{array}$ & 30 & 26,44 & 78,67 & 1,25 & 2,00 & 1,67 & $\begin{array}{c}\text { Tidak Ada } \\
\text { Kontrol }\end{array}$ \\
& 31 & 23,84 & 53,13 & 1,25 & 2,00 & 1,67 & \\
\hline $\begin{array}{c}\text { Rata-rata } \\
\text { Posttest }\end{array}$ & $\begin{array}{l}\text { Eksperime } \\
\mathrm{n}\end{array}$ & 30 & 53,63 & 177,94 & 2,79 & 2,00 & 1,67 & Terdapat \\
& Kontrol & 31 & 45,03 & 111,76 & 2,79 & 2,00 & 1,67 & \\
\hline
\end{tabular}


Hasil uji perbedaan rata-rata pretest THBK menunjukkan bahwa tidak terdapat perbedaan kemampuan awal siswa kelas eksperimen dan siswa kelas kontrol, sehingga pengaruh bisa dilihat dari hasil uji perbedaan rata-rata nilai posttest THBK kedua kelas. Hasil uji perbedaan rata-rata posttest THBK menunjukkan bahwa terdapat perbedaan hasil belajar kognitif antara kelas eksperimen dan kelas kontrol.

Hasil ini sejalan dengan hasil penelitian yang diperoleh Sijabat dan Motlan (2016) [11]. Berdasarkan hasil penelitiannya didapatkan bahwa ada perbedaan hasil belajar yang menggunakan model pembelajaran problem solving dan model konvensional, yaitu siswa yang belajar dengan model problem solving memiliki hasil belajar yang lebih baik. Hasil penelitian Siregar dan Siregar (2014) juga menunjukkan bahwa terdapat pengaruh pembelajaran problem solving terhadap hasil belajar siswa pada materi listrik dinamis dibandingkan menggunakan model pembelajaran langsung [12]. Selanjutnya Tampubolon dan Sitindaon (2013) juga memperoleh hasil penelitian yang serupa pada materi optika geometris, yaitu model pembelajaran problem solving dapat meningkatkan hasil belajar siswa kelas $\mathrm{X}$ SMA Negeri 7 Medan pada materi optika geometris [13]. Hasil penelitian Purwanti dan Manurung (2015) juga menunjukkan hasil yang serupa, yaitu terdapat perbedaan hasil belajar fisika siswa dengan model pembelajaran Problem Solving dan Direct Instruction [14].

Pembelajaran problem solving memberikan siswa kesempatan untuk melakukan kegiatan, merasa nyaman saat melakukan pembelajaran, aktif bertanya, dan aktif meningkatkan hasil belajar [14]. Melalui pembelajaran dengan model PSF siswa kelas eksperimen yang belajar menggunakan model Problem Solving Fisika dilatih untuk memahami masalah yang diberikan, kemudian menuliskan kembali masalah tersebut baik secara kualitatif maupun secara fisika, merencanakan langkah pemecahan, dan kemudian menjalankan rencana. Siswa kelas eksperimen telah diajarkan untuk selalu memahami dulu soal tes yang diberikan, sebelum menyelesaikannya langsung dengan persamaan matematis, sedangkan siswa yang belajar menggunakan model pembelajaran langsung lebih cenderung menghafal, karena selama proses pembelajaran berlangsung guru menjadi sumber belajar utama dan siswa tidak memiliki kesempatan untuk aktif di kelas.

Pembelajaran pada kelas eksperimen yang menggunakan model PSF mengajarkan siswa untuk bisa berdiskusi bersama temannya dalam kelompok kecil yang terdiri dari tiga hingga empat orang. Benckert dan Petterson (2008) menyatakan bahwa pembelajaran problem solving melalui kelompok kecil, siswa dapat mendiskusikan konsep dan prinsip fisika serta menyalurkan pengetahuan mereka sehingga miskonsepsi yang mereka peroleh dari pembelajaran bisa diperbaiki bersama antara sesama siswa maupun siswa dengan guru [15]. Hal ini menjadi faktor mengapa siswa kelas eksperimen memperoleh hasil belajar yang lebih tinggi daripada kelas kontrol. Siswa kelas eksperimen belajar melalui kelompok kecil yang terdiri dari 3 hingga 4 orang sehingga mereka bisa saling berbagai informasi. Mereka saling membantu dalam menyelesaikan LKS PSF dan memecahkan masalah yang diberikan. Siswa yang memiliki pemahaman lebih dalam fisika membantu siswa yang memiliki pemahaman yang kurang. Oleh sebab itu pembagian kelompok harus benar-benar merata dan heterogen. Melalui model PSF siswa diajarkan untuk selalu memahami soal yang diberikan sebelum memasukkan rumus dan menyelesaikan soal yang diberikan. Siswa juga diajarkan bagaimana menuliskan besaran dan satuan fisika secara tepat. Selain itu, model pembelajaran PSF dapat meningkatkan hasil belajar siswa [16].

Berbeda dengan siswa kelas eksperimen, siswa kelas kontrol cenderung bekerja secara individual. Mereka seolah-olah bersaing untuk terlihat menonjol di depan guru, sehingga siswa yang cenderung lambat mengolah informasi dan siswa yang memiliki pemahaman yang kurang menjadi terasingkan. Siswa kelas kontrol cenderung terburu-buru dalam menyelesaikan soal dengan memasukkan angka dan menyelesaikan perhitungan tanpa memahami kembali masalah yang diberikan.

Hasil analisis uji perbedaan menggunakan uji t menunjukkan bahwa terdapat perbedaan hasil belajar kognitif antara kelas eksperimen dan kelas kontrol. Karena terdapat perbedaan, 
maka dapat disimpulkan bahwa pembelajaran menggunakan model PSF memberikan pengaruh terhadap hasil belajar kognitif siswa. Selanjutnya untuk mengukur seberapa besar pengaruh (effect size) yang diberikan oleh pembelajaran dengan menggunakan model PSF terhadap hasil belajar kognitif, perlu dilakukan uji lanjut menggunakan rumus Cohen's $d$. Hasil perhitungan yang diperoleh menunjukkan bahwa pengaruh yang diberikan oleh pembelajaran menggunakan model PSF berada dalam kategori sedang atau medium, yaitu sebesar 0,72. Artinya model PSF memberikan pengaruh sebesar $76 \%$ terhadap hasil belajar kognitif, dan 24\% lainnya dipengaruhi oleh faktor lain.

\subsection{Pengaruh Model PSF terhadap Kemampuan Pemecahan Masalah Fisika}

Kemampuan pemecahan masalah fisika adalah kemampuan yang dimiliki oleh siswa setelah melalui proses belajar fisika dengan menerapkan konsep yang diterimanya ke dalam masalah untuk menemukan solusi. Kriteria kemampuan pemecahan masalah fisika (KPMF), terdiri dari lima sub kriteria, yaitu Kemampuan Memahami Masalah secara Umum (KMMU), Kemampuan Memahami Masalah secara Fisika $(K M M F)$, Kemampuan membuat rencana pemecahan masalah $(K M R P)$, Kemampuan menjalankan rencana $(K M R)$, dan Kemampuan Menghitung $(K M)$.

Hasil tes kemampuan pemecahan masalah fisika dianalisis secara terpisah dengan soal tes hasil belajar kognitif. Skor maksimum tes kemampuan pemecahan masalah fisika adalah 15 dan skor minimumnya adalah 5. Skor ini kemudian dikonversi menjadi nilai dalam rentang 1-100. Untuk melihat ada tidaknya pengaruh kemampuan awal siswa dan proses pembelajaran yang dialami oleh siswa terhadap kemampuan pemecahan masalah, maka dilakukan pengurangan nilai rata-rata posttest dengan nilai rata-rata pretest. Data hasil tes kemampuan pemecahan masalah ditunjukkan dalam Tabel 5.

Tabel 5. Data Kemampuan Pemecahan Masalah Fisika Siswa Kelas Eksperimen

\begin{tabular}{lcc}
\hline \multicolumn{1}{c}{ Deskripsi } & Pretest & Posttest \\
\hline Nilai Rata-rata & 40,59 & 60,22 \\
Nilai Tertinggi & 80,00 & 88,89 \\
Nilai Terendah & 8,89 & 40.00 \\
Standar Deviasi & 16,00 & 13,98 \\
Gain & \multicolumn{2}{c}{19,56} \\
\hline
\end{tabular}

Berdasarkan kriteria kemampuan pemecahan masalah fisika menurut Warimun [7], Rata-rata pretest KPMF siswa berada dalam kategori kurang dan rata-rata posttest KPMF siswa berada pada kategori baik. Hasil gain menunjukkan bahwa pembelajaran menggunakan model PSF berpengaruh terhadap kemampuan pemecahan masalah fisika siswa. Hasil perhitungan effect size menunjukkan bahwa pengaruh yang diberikan oleh model PSF terhadap KPMF berada dalam kategori kuat, yaitu sebesar 1,80. Artinya model PSF memberikan pengaruh sebesar $96,4 \%$ terhadap kemampuan pemecahan masalah fisika siswa.

Hasil penelitian ini sesuai dengan penelitian sebelumnya yang dilakukan oleh Warimun (2010;2012;2017) menyimpulkan bahwa model PSF dapat meningkatkan kemampuan problem solving fisika pada konsep optika dan kesetimbangan benda tegar. Selanjutnya Rimadani, Parno, dan Diantoro (2014) menyimpulkan bahwa kemampuan pemecahan masalah siswa berada dalam kategori sedang pada materi suhu dan kalor yang dibelajarkan menggunakan model pembelajaran problem solving [4]. Pembelajaran problem solving memberikan pengaruh yang positif, dimana saat siswa berdiskusi, siswa bisa saling berbagi pengetahuan, berdiskusi dengan sesama teman dan guru, memperbaiki miskonsepsi selama diskusi, dan menerapkan pemecahan masalah dengan tepat [16]. Hasil yang sama juga diperoleh Gok dan Silay (2010) dari penelitiannya, bahwa alasan tingginya kemampuan pemecahan masalah yang dimiliki oleh siswa yang belajar menggunakan model problem solving adalah penerapan tahapan pemecahan masalah yang sistematis, antusias siswa saat belajar, dan pembelajaran yang berpusat pada siswa [18]. 
Model pembelajaran Problem Solving Fisika menurut Siregar dan Siregar (2014) mampu membuat siswa bisa berpikir secara sistematis, karena mereka dituntut untuk menyelesaikan masalah dengan menggunakan tahapan pemecahan masalah fisika; mampu menganalisis masalah yang diberikan baik secara kualitatif maupun secara kuantitatif; mengajarkan siswa untuk berpikir sebelum bertindak, karena siswa diharuskan menuliskan rencana pemecahan masalah sebelum menjalankan rencana pemecahan masalah [12]. Selanjutnya hal yang menjadi kelebihan sekaligus kekurangan model PSF adalah hanya bisa diterapkan dalam pembelajaran fisika saja, sehingga tidak bisa diterapkan di mata pelajaran lainnya. Model PSF merupakan model pembelajaran satu-satunya yang khusus untuk diterapkan dalam pembelajaran fisika.

Kekurangan model PSF ini adalah dibutuhkan waktu yang lama untuk proses pembelajaran di kelas, sehingga guru harus mampu untuk mengatur alokasi waktu dengan baik. Menurut Syahputri dan Tampubolon (2014), siswa yang tidak memiliki minat atau kepercayaan bahwa masalah yang diberikan sulit untuk dipecahkan akan enggan untuk mencoba [1]. Namun apabila siswa lebih sering dilatih untuk memecahkan masalah, siswa akan menjadi pemecah masalah yang handal dan semakin tertantang untuk memecahkan masalah sehingga siswa yang enggan untuk mencoba akan berkurang.

\section{SIMPULAN DAN SARAN \\ 4.1. Simpulan}

Berdasarkan hasil analisis data dan pembahasan yang telah dilakukan dapat disimpulkan bahwa, 1) terdapat pengaruh pembelajaran menggunakan model PSF terhadap hasil belajar kognitif sebesar 0,72 yang berada pada kategori sedang; dan 2)Terdapat pengaruh model pembelajaran PSF terhadap kemampuan pemecahan masalah fisika siswa sebesar 1,80 yang berada dalam kategori kuat.

\subsection{Saran}

Berdasarkan penelitian yang telah dilakukan, disarankan beberapa hal yaitu, 1) model pembelajaran Problem Solving Fisika dapat digunakan sebagai salah satu model alternatif oleh guru dalam pembelajaran fisika; 2) sebelum diterapkan, guru sebaiknya memahami model ini dengan baik agar didapatkan hasil yang maksimal; 3) guru harus bisa mengatur alokasi waktu dengan baik agar pembelajaran dengan model PSF bisa dilakukan dengan efektif, hal ini dikarenakan pembelajaran dengan model PSF membutuhkan waktu yang cukup lama; dan 3) Model PSF sebaiknya lebih sering diterapkan di kelas dalam materi fisika lainnya, agar siswa lebih berpengalaman dalam memecahkan masalah.

\section{DAFTAR PUSTAKA}

[1] Syahputri, R., \& Tampubolon, T. (2014). Pengaruh Model Pembelajaran Problem Solving Terhadap Hasil Belajar Fisika Siswa Kelas VIII SMP Negeri 1 Sipispis T.P 2012/2013. Jurnal Inpafi, 1-9.

[2] Hegde, B. (2012). How do they solve it? An insight into the learner's approach to the mechanism. Physics Education Research, 1(8), 1-9.

[3] Taale, K. D. (2011). Improving physics problem solving skills of students of Somaya Senior High Secondary Technical School in The Yilo Krobo District off Eastern Region of Ghana. Journal of Education and Practice, 2(6), 8-20.

[4] Rimadani, E., Parno, \& Diantoro, M. (2014). Penguasaan Konsep dan Kemampuan Pemecahan Masalah Siswa SMA pada Materi Suhu dan Kalor. Semnas Pendidikan IPA Pascasarjana UM. 1, hal. 108-112. Semarang: Universitas Malang.

[5] Aqib, Z., \& Mutadlo. (2016). Kumpulan Metode Pembelajaran Kreatif dan Inovatif. Bandung: PT Sarana Tutorial Nurani Sejahtera.

[6] Warimun, E. S. (2010). Pengembangan Kemampuan Problem Solving melalui Pembelajaran Topik Optika Bagi Mahasiswa Calon Guru Fisika. Bandung: Tidak Diterbitkan. 
[7] Warimun, E. S. (2017). Peningkatan Keterampilan Problem Solving Mahasiswa melalui Pembelajaran dengan Model Problem Solving pada Materi Kesetimbangan Benda Tegar. Seminar Magister Pendidikan Dasar (hal. 113-119). Bengkulu: FKIP Universitas Bengkulu.

[8] Sugiyono. (2010). Metode Penelitian Pendidikan. Bandung: Alfabeta.

[9] Thalheimer, W., \& Cook, S. (2002, Agustus). bwgriffin. Dipetik Mei 7, 2018, dari WorkLearning Research: http://www.bwgriffin.com/gsu/courses/edur9131/content/Effect_Sizes_pdf5.pdf

[10] Kadel, R. P., \& Kip, K. E. (2012). A SAS Macro to Compute Effect Size (Cohen's) and its Confidence Interval. Florida: University of South Florida.

[11] Sijabat, A., Motlan, \& Derlina. (2016). Pengaruh Model Pembelajaran Model Problem Solving dan Pemahaman Konsep Terhadap Hasil Belajar Fisika Siswa. Jurnal Pendidikan Fisika, 5(2), 87-91.

[12] Siregar, D. P., \& Siregar, N. (2014). Pengaruh Model Pembelajaran Problem Solving Terhadap Hasil Belajar Siswa pada Materi Listrik Dinamis di Kelas X SMA Mulia Medan TP 2012/2013. Jurnal Inpafi, 2(3), 54-62.

[13] Tampubolon, T., \& Sitindaon, S. F. (2013). Pengaruh Pembelajaran Problem Solving Terhadap Hasil Belajar Siswa Kelas X SMA Negeri 7 Medan. Jurnal Inpafi, 1(3), 260-268.

[14] Purwanti, S., \& Manurung, S. (2015). Analisis Pengaruh Model Pembelajaran Problem Solving dan Sikap Ilmiah Terhadap Hasil Belajar Fisika. Jurnal Pendidikan Fisika, 4(1), 57-62.

[15] Benckert, S., \& Pettersson, S. (2008). Learning Physics in Small-Group DiscussionsThree Examples. Eurasia Journal of Mathematics, Science, Technologi, Education, 4(2), 121-134.

[16] Gok, T., \& Silay, I. (2008). Effects of Problem Solving Strategies Teaching on Problem Solving Attitudes of Cooperative Learning Group in Physics Education. Journal of Theory and Practice in Education, 4(2), 253-266.

[17] Warimun, E. S. (2012). Pengembangan Model Pembelajaran Problem Solving Fisika melalui Pembelajaran Topik Optika pada Mahasiswa Pendidikan Fisika. Seminar Nasional Fisika. 13, hal. 188-192. Palembang: Prosiding Seminar Nasional Fisika.

[18] Gok, T., \& Silay, I. (2010). The Effects of Problem Solving Strategies on Students' Achievement, Attitude and Motivation. Physics Education Journal, 7-21. 